Egypt. J. Aquat. Biol. \& Fish., Vol. 12, No.1:143-154 (2008) ISSN 1110-1131

\title{
Apoptosis phenomenon of gonadal cells during sex-reversal in the bony fish Rhabdosargus haffara.
}

\author{
Amal M. Ramadan \\ National Institute of Oceanography and Fisheries, \\ Red Sea and Suez \& Aqaba Gulfs Branch \\ P. O. Box 182, Suez, Egypt \\ amalr66@yahoo.com
}

\begin{abstract}
The purpose of this study was to demonstrate the normal occurrence of programmed cell death (apoptosis) in the gonads (testes and ovaries) of the fisii Rhabdosargus haffara during sex-reversal process. Histological evidence marked apoptosis in function male during transformation of gonads from male to female, where there was decrease in size of testis with condensed spermatogonia and closed spermatic ducts with residual sperm. On the other hand, oocyte apoptosis in $R$. haffara occurs in three common stages: which start at the wall of oocytes. The first stage includes shrinkage of oocyte size. Theca and granulosa of apoptotic oocyte transformed to. phagocytic cells. In the second type protrusions appear in the oocyte wall until the oocite looses its identity and displayed amoeboid shape with liquefied content. The third stage depends on the breaking down of oocytes wall into small fragments. Finally, all types of apoptosis lead to lysis and loss of oocyte content. The importance of this phenomenon with sex-reversal may lead to social interactions and the natural balance in the $R$. haffara population.
\end{abstract}

Key words: apoptosis, sex - reversal, Rhabdosargus haffara, gonadal cells

\section{INTRODUCTION}

Hermaphroditism is expressed in $15 \%$ of teleost families (Lau and Sadovy, 2001). The term apoptosis was illustrated as programmed cell death during sex-reversal or sex differentiation of fish (Uchida et al., 2002).

Apoptosis is a form of cell death that plays a major role during the normal development and homeostasis of multicellular organisms (Sinha Hikim and Swerdloff, 1999). Germ cell apoptosis occurs during spermatogenesis of various mammalian species, and plays an important role in determining sperm output (Sharpe, 1994). In mammalian spermatogenesis, apoptosis occurs mainly at the level of spermatogonia (Dunkel et al., 1997; Rodriguez et al., 1997) or spermatocytes (Young et al., 1999; Strbenc et al., 2003). Proliferation and apoptosis of male germ cells have been observed in different seasonally bred mammals (Blottner et al., 1995; Young and Nelson, 2001; Strbenc et al., 2003). 
Scott et al. (1980), Billard et al. (1982), Kime and Manning (1982), Borg (1994) and Weltzien et al. (2002) studied the role of apoptosis in the regulation of reproduction of teleosts. Few investigations have been carried out on cartilaginous fishes such as the shark Squalus achantias L., where apoptosis has been documented at the level of spermatogonia and preleptotene spermatocytes (Callard et al., [995).

Rhabdosargus haffara is one of the most abundant fish species in Suez Bay. Previous publications have described the gonads of these fish as having two distinct forms in the beginning of their life; a) protandrous hermaphroditism in the majority and b) ovaries only do not have any hermaphroditic structure (ELHalfaw: 2001). Fish oocytes generally have three distinct layers, namely, an outermost follicular layer, a median zona radiata (ZR) and an inner oolemma or oocyte plasma membrane. The follicular layer consists of an outer theca and an inner granulosa layer.

Apoptosis phenomenon in this fish has not so far been studied during the gonad transformation, from testis to ovary or from ovary to testis. The present study is therefore, focused on this phenomenon and its role in sexreversal.

\section{MATERIALS AND METHODS}

Specimens of the fish $R$. haffara were collected from commercial catch at Alaga harbor Suez Bay. Fish were dissected and gonads were taken out to be fixed in Bouin's solution. The fixed gonad samples were dehydrated in ethano! and embedded in paraffin wax. The gonads were sectioned at $7 \mu \mathrm{m}$ in thickness. The sections were de-paraffinized in xylene and stained with haematoxylin eosin and Milligan trichrome stains. The stained sections were examined under Nikon microscope. Photomicrographs were taken to illustrate apoptosis.

\section{RESULTS}

The present study showed that Rhabdosargus hafara starts its life as fernale only or hermaphrodite male. After the first spawning season, groups of the functional male are transformed into functional female. During this process, apoptosis helps in the transformation steps as follows:

A- Apoptosis in the normal testis cells:-

The transformation of functional male to female (in this case the testes in spent stage and the ovaries cells are arrested on perinucleolus stage). At the beginning of this process, ovarian size increases and testicular size decreases. The spermatogonia, which line the wall of spermatic lobules in addition to the residuals of spermatozoa are scattered in the gonadal stroma (Fig. 1). Then, the lobule lumens are closed and the spermatic duct appears coalesced (Fig. 2). Finally, the testicular lobe appears reduced in size and attached to the active ovary wall (Fig. 3). 


\section{B- Apoptosis in the normal ovaries:-}

Ovaries of $R$. haffara demonstrated apoptosis of oocytes in females at spent stage or at the onset of ovary transformation, where fish behaviour is function female with rudimentary testes. Histological investigation of ovaries showed the manner of transformation from ovary to function male; it is correlated with inactive ovary, which is reduced in size where the oocytes start the mechanisms of death in major three types and the testis began to be active as follows:

1- First type:-

The apoptotic signs in this type are:-

I a- The oocyte wall becomes more thickened than the normal one (Fig. 4).

I $b$ - The oocyte wall thickens more and more and the oocyte size is reduced (Fig. 5).

I c- The oocyte looses its identity and it's wall is converted into phagocytic cells (Fig. 6).

\section{II- Second type:-}

The apoptotic signs are as follow:-

Il a- The oocyte wall convoluted (Fig. 7).

II b-The oocyte contents (yolk, cytoplasm and nucleus) liquefied and become irregular forming an amoeboid shape (Fig. 8).

III- The third type:-

III a- The oocyte wall became slightly thickened than normal and the oocyte contents liquefied. The follicular layer consists of an outer theca and an inner granulosa layer, where they display destruction (Fig. 9).

III $b$ - The follicular layer fragments increase in number and loose their identity (Fig. 10).

Finally, the apoptotic oocytes lysed and lost their ooplasm contents in the three mentioned types (Figure 11).

\section{DISCUSSION}

Apoptosis induced by genetic sex determination, environmental factors such as heat, stress, low $\mathrm{pH}$, salinity, nutrition and exogenous estrogen and androgen levels are known to influence the determination of phenotypic sex in fish (Shapiro, 1990; Korpelaninen, 1990; Kitano et al., 1999). Kurita et al. (2003) stated that atresia is associated with variable energy resources and environmental conditions. This phenomenon is found in Rhabdosargus haffara during sexreversal as shown in the present results in both male and female. So, apoptosis in Rhabdosargus haffara is correlated with hermaphroditism and sex reversal in testes and ovaries and these results agree with Wang et al. (2007) who mentioned that apoptosis occurred in sex differentiation and sex change in adult teleosts. The testes undergo a remarkable atrophy due both to reduction of cell 
size and to cell deatl (Young and Nelson, 2001). Testis enters a drastic formation process, which initiates the conversion of such testis into ovary.

Corrieroa et al.(2007) stated that apoptosis occurs throughout the reproductive season although it's maximal is at the onset of spermatogenesis. Our results illustrated that apoptotic male is similar to spent stage. During sex reversal testes and spermatic lobules became reduced in size with scattered residuals of sperms, but the spermatic ducts of the testis is coalesced. These observations tempt uI to suggest that spontaneous degeneration of spermatogenesis is demonstrated at all the developmental stages. These observations on transformed male agree with Uchida et al. (2002); they mentioned that apoptotic spermatogonia were observed in sex differentiation. Apoptotic spermatogonia, spermatocytes and condensed cells were located in the same lobule beside large number of apoptotic spermatids. During differentiation, the gonads of male zebra fish go through a process similar to that of sequential hermaphrodite teleost that changes sex from female to male during adulthood (Frisch, 2004).

Subsequent histological analysis of another batch of ovaries clears that the wall of the oocyte plays an essential role in the apoptotic process and this result agrees with that obtained by Ramadan et al. (1987), who indicated that deformation of the wall of the oocyte was considered as the first step of atresia (rentention or apoptosis) and phagocytosis of oocytes. Our observations agree with the results obtained by Ramadan and EL-Halfawy (2007); they mentioned that about $30 \%$ to $35 \%$ of the ova became atretic in Rhabdosargus haffara as a natural phenomenon and there were two types: burasting atresia and nonburasting atresia.

Apoptosis is a form of cell death that plays a major role during development of multicellular organisms (Sinha Hikim and Swerdloff, 1999) These findings suggest that apoptosis takes place in Rhabdosargus hafjara in three major types that include thickening of the oocyte, fragmentation or protrusion; and finally all the prouucts lyse. So, apoprotic phenomenon may achieve a natural balance to the pupulation and optimum sex-ratio which fish community needs it in the hermaphrodite fishes. Ramadan and EL-Halfawy (2007) mentioned that atresia (apoptosis) may be important as it affects the estimated spawning potential of the stock.

In conclusion our findings suggest that programmed cell death mechanisms occur in Rhabdosargus haffara during sex-reversal occurs as a normal phenomenon after first spawning season of this fish. The essential importance of this phenomenon in Rhabdosargus haffara may achieve natural balance to the fish population (social interaction).

\section{ACKNOWLEDGMENT}

My deep thanks are to Dr. Magdy M. EL-Halfawy, researcher in the National Institute of Oceanography and Fisheries (NIOF) for his advice and 
helpful comments. Also, I would like to thank the institute (NIOF) staff members in Suez for the support offered to me.

\section{REFERENCES}

Billard, R. ; Jalabert, B. and Breton. B. (1972). Les cellules de Sertoli des poisons te' le' oste' ens. I. E' tude ultrastructurale. Annales de Biologie Animale, Biochimie et Bioply sique, 12: 19-32.

Blottner, S.; Hingst, O. and Meyer. H. H. D. (1995). Inverse relationship between testicular proliferation and apoptosis in mammalian seasonal breeders. Theriogenology, 44:320-328.

Borg, B. (1994). Androgens in teleost fishes. J. Comp. Bioch. Pliy'siol., 109C: 219-245.

Callard, G. V.; Jorgensen, J. C. and Redding, J. M. (1995). Biochemical analysis of programmed cell death during premeiotic stages of spermatogenesis in vivo and in vitro. Developmental Genetics, 16: 140-147.

Corriero A.; Desantis S.; Bridges C. and Kime D. E. (2007). Germ cell proliferation and apoptosis during different phases of sword fish (Xiphias gladius L.) spermatogenetic cycle. J. Fish Biol., 70:83-99.

Dunkel, L; Hirvonen, V. and Erkkila. K. (1997). Clinical aspect of male germ cell apoptosis during testis development and spermatogenesis. Cell Death and Differentiation, 4: 171-179.

Frisch A. (2004). Sex-change and gonadal steroids in sequentiallyhermaphroditic teleost fish. Rev. Fish Biol. and Fisheries, 14: 481-499.

Kime, D. A. and Manning, N. J. (1982). Seasonal patterns of free and conjugated androgens in the brown trout Salmo trutta. General and Comp. Endocrinol., 48: 222-231.

Kitano T.; Takamune K.; Kobayashi T.; Nagahama, Y. and Abe, S. I. (1999). Supperssion of $P 450$ aromatase gene expression in sex revervsed males produced by rearing genetically female larvae at high water temperature during period of sex differentiation in the Japanese flounder Paralichthys olivaceus. J. Molec. Endocrinol., 23: 167-176.

Korpelainen, H. (1990). Sex ratios and conditions required for environmental sex determination in animals. Biol. Rev., 65: 147-184. 
Kurita, Y.; Meier, S. and Kyesbu, O. S. (2003). Oocyte growth and fecundity regulation by atresia of atlantic herring (Clupe harengus) in relation to body condition throughout the maturation cycle. J. Sea Res., 49: 203219.

Lau, P. P. F. and Sadovy, Y. (2001). Gonad structure and sexual pattern in two thread fin breams and possible function of the dorsal accessory duct. J. Fisin Biol., 58: 1438-1453.

Ramadan, A. A.; Ezzat, A. A.; Khadre. S. E. M; Muguid, N. A. and Aziz ElSha. (1987) Seasonal histological changes in the ovary of Spartis aurata, a hermaphrodite teleost marine fish (Family: Sparidae). Folia Morph., 35(3): 251-264.

Ramadan, A. M. and EL-Halfawy, M. M. (2007). Common forms of atresia in the ovary of some Red sea fishes during reproductive cycle. Pakistan J. Biol. Sci., 10(18): 3120-3125.

Rodriguez, 1.; Ody, C.; Araki, K.; Garcia, 1. and Vassalli, P. (1997). An early and massive wave of geminal cell apoptosis is required for the development of functional spermatogenesis. EMBO J., 16: 2262-2270.

Scott, A. P.; Bye, V. J.; Baynes, S. M. and Springate, J. C. R. (1980). Seasonal variation in plasma concentration of 11-ketotestosterone and testosterone in male rainbow trout, Salmo gairdnerii Richardson. J. Fish Biol., 17: 495-505.

Shapiro, D. Y. (1990). Sex changing fish as a manipulable system for the study of the determination, differentiation and stability of sex in vertebrates. J. Exp. Zool. Suppl,. 4: 132-136.

Sharpe, R. M. (1994). Regulation of spermatogenesis. In The Physiology of Reproduction (Knobil, E. \& Neill, J. D., eds), pp. 1363-1434. New York: Raven Press.

Sinha Hikim, A. P. and Swerdloff, R. S. (1999). Hormonal and genetic control of germ cell apoptosis in the testis. Reviews of Reproduction, 4: 38-47.

Strbenc, M.; Fazarinc, G.; Bavdek, V. and Pogacnik, A. (2003). Apoptosis and proliferation during seasonal testis regression in the brown hare (Lupus europaeus L.). Anatomia Histologia Embryologia, 32: 48-53. 
Uchida, D.; Yamashita, M.; Kitano, T. and Iguchi, T. (2002) Oocyte apoptosis during the transition from ovary-like tissue to testes during sex differentiation of juvenile Zebrafish. J. Exp. Boil., 205: 711-718.

Wang, X. G.; Bartfai, R.; SL-eptsova-Freidrich, I. and Orban, L. (2007). The timing and extent of juvenile ovary phase are highly variable during zebrafish testis differentiation. J. Fish Biol., 70: 33-44.

Weltzien, F.-A.; Taranger, G. L.; Karlsen, D. and Norberg, B. (2002). Spermatogenesis and related androgen levels in Atlantic halibut (Hippoglossus hippoglossus L.). Comp. Biochem. Physiol., $132 \mathrm{~A}$ : 567-575.

Young, K. A.; Zirkin, B. R. and Nelson, R. J. (1999). Short photoperiod induces testicular apoptosis in the white-footed mouse (Peromyscus leucopus). Endocrinology, 140: 3131-3139.

Young, X. A. and Nelson, R. J. (2001). Mediation of seasonal testicular regression by apoptosis reproduction. J. Society for Reproduction and Fertility, 122: 677-685. 


\section{LIST OF FIGURES}

Figure 1. Micrograph of apoptotic Rhabdosargus haffara testis showing spermatozoa scattered in the gonadal stroma. (haematoxylin-eosin stain $10 \mathrm{X}$ ).

Figure 2. Micrograph of Rhabdosargus haffara testis showing the lumens closed and the spermatic ducts are coalesced. (haematoxylin-eosin stain - 10X).

Figure 3. Micrograph of apoptotic Rhabdosargus haffara testis showing testis lobe attached to ovary wall (arrow).. (haematoxylin-eosin stain - 5X).

Figure 4. Micrograph of apoptotic, ovary of Rhabdosargus haffara, type I shows a thickened oocyte wall. (Milligan trichrome stain - 20X).

Figure 5. Micrograph of apoptotic Rhabdosargus haffara ovary, type I b, showing decrease in size of the follicular wall. (Milligan trichrome stain $-20 X)$

Figure 6. Micrograph of apoptotic of ovary Rhabdosargus haffara, type I c, showing condensed oocytes and phagocytic cells (arrow). (Milligan trichrome stain - 20X).

Figure 7. Micrograph of apoptotic ovary of Rhabdosargus haffara, type II a, showing folded oocyte wall. (Milligan trichrome stain - 20X).

Figure 8. Micrograph of apoptotic Rhabdosargus haffara ovary, type II b, showing liquefied content and amoeboid shape oocyte. (Milligan trichrome stain - 20X).

Figure 9. Micrograph of apoptotic ovary of Rhabdosargus haffara, type III a, showing breaking down of the wall into fragments (haematoxyiin-eosin stain - 20X).

Figure 10. Micrograph of apoptotic of ovary Rhabdosargus haffara, type III b, showing liquefied content of oocyte and increased number of wall fragments. (haematoxylin eosin stain - 20X).

Figure 11. Micrograph of apoptotic ovary of Rhabdosargus haffara showing lysis of oocyte (haematoxylin-eosin stain - 20X). 


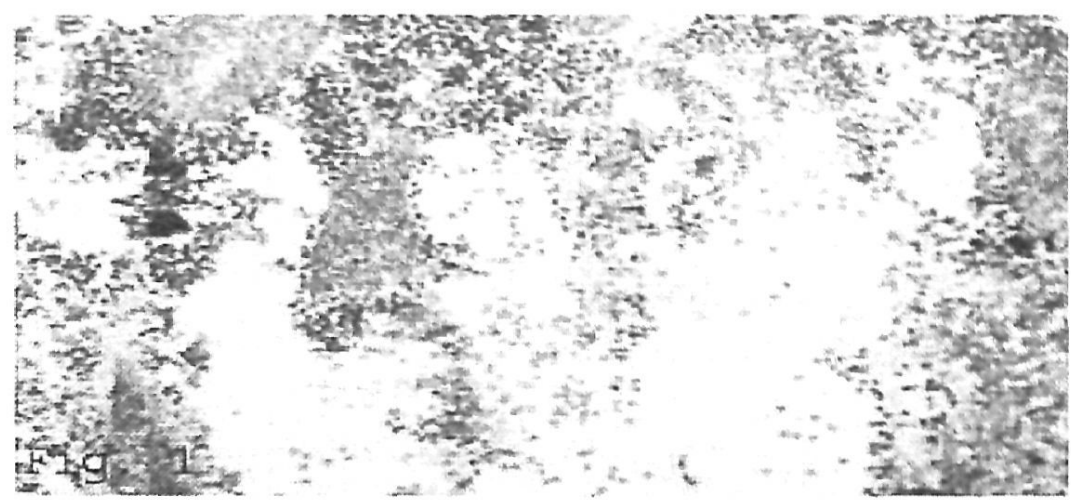

Fig. 2
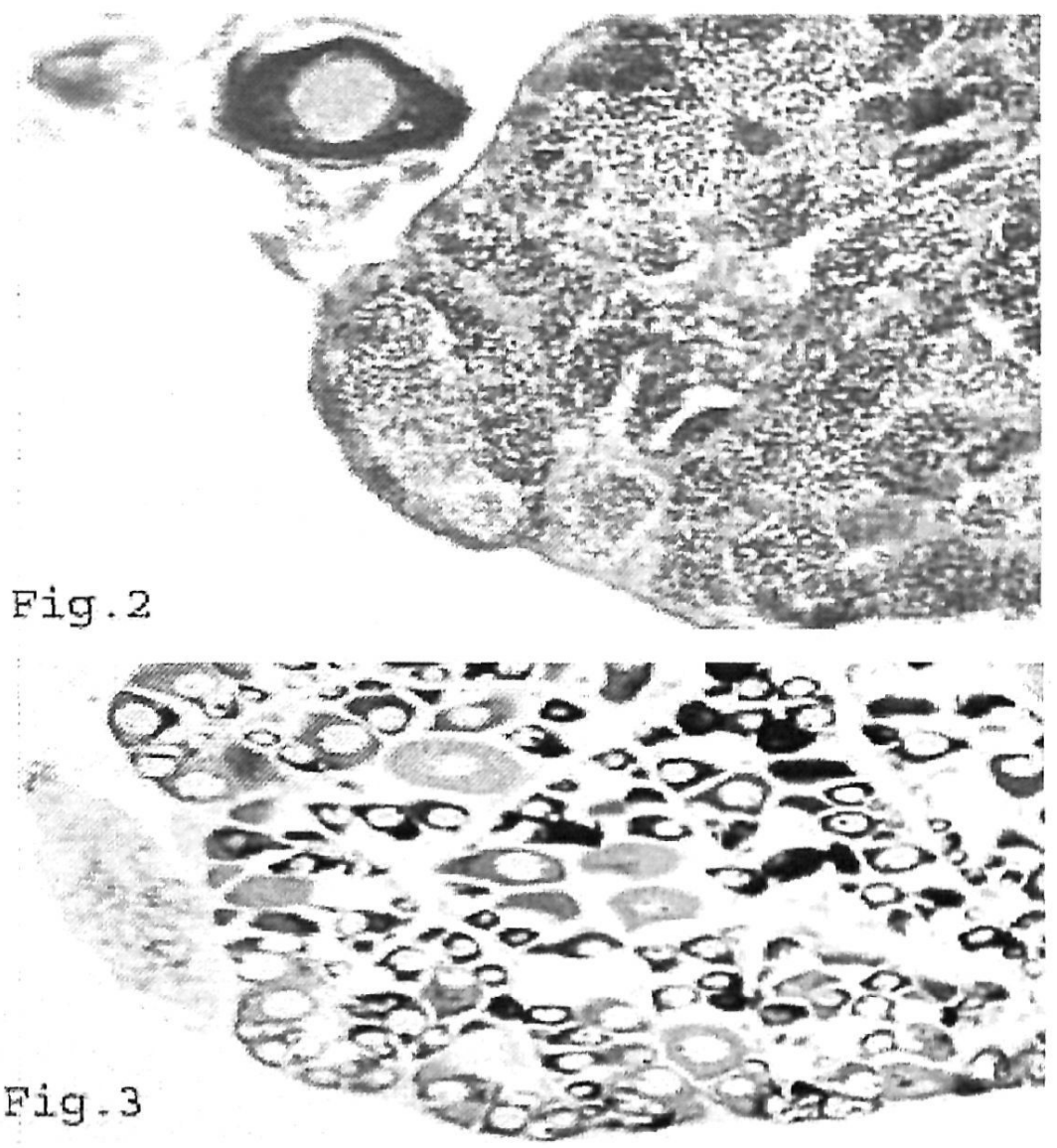

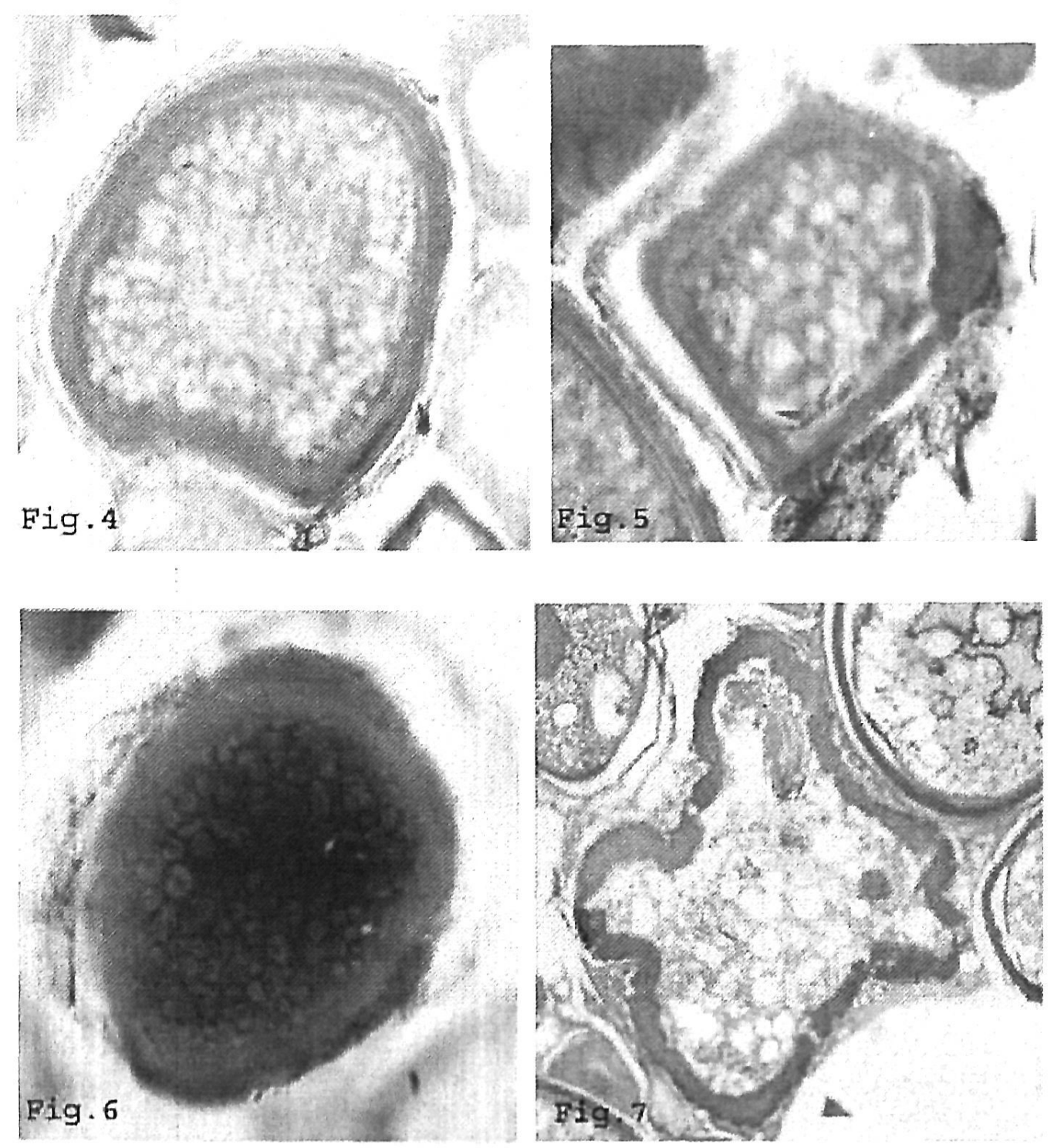


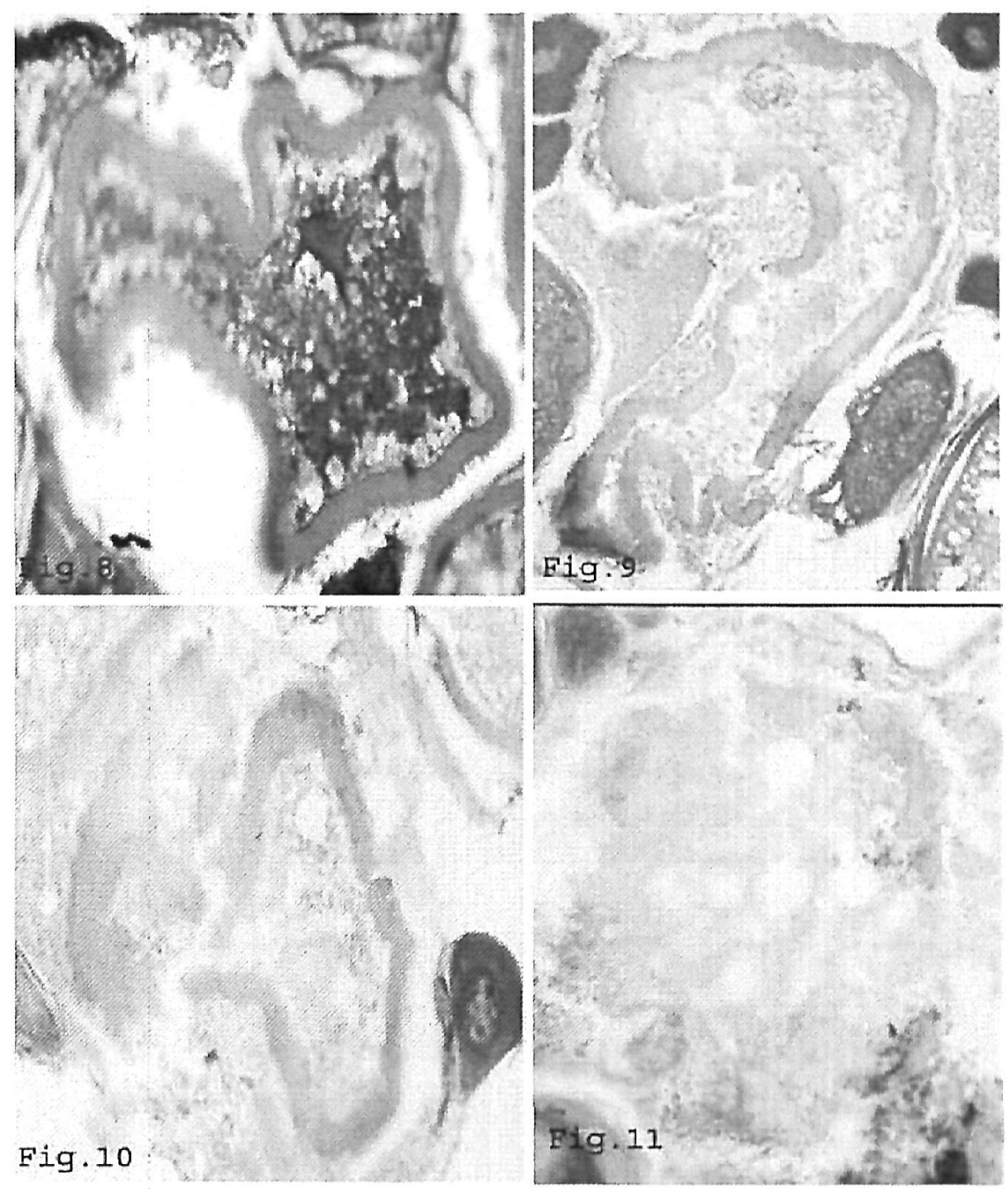

